\title{
Iron absorption in hepcidin1 knockout mice
}

\author{
Patarabutr Masaratana ${ }^{1,2}$, Abas H. Laftah ${ }^{1}$, Gladys O. Latunde-Dada ${ }^{1}$, Sophie Vaulont ${ }^{3}$, \\ Robert J. Simpson ${ }^{1}$ and Andrew T. McKie ${ }^{1_{*}}$ \\ ${ }^{1}$ Nutritional Sciences Research Division, King's College London, 150 Stamford Street, London SE1 9NH, UK \\ ${ }^{2}$ Department of Biochemistry, Faculty of Medicine Siriraj Hospital, Mabidol University, Bangkok, Thailand \\ ${ }^{3}$ Département de Génétique, Développement et Pathologie Moléculaire, Institut Cochin, Institut National de la Santé et de la \\ Recherche Médicale U567, Paris, France
}

(Received 12 April 2010 - Revised 9 November 2010 - Accepted 12 November 2010 - First published online 8 February 2011)

\section{Abstract}

Hepcidin, the Fe-regulatory peptide, has been shown to inhibit Fe absorption and reticuloendothelial Fe recycling. The present study was conducted to explore the mechanism of in vivo Fe regulation through genetic disruption of hepcidin 1 and acute effects of hepcidin treatment in hepcidin 1 knockout $\left(H e p c 1^{-/}\right.$) and heterozygous mice. Hepcidin1 disruption resulted in significantly increased intestinal Fe uptake. Hepcidin injection inhibited Fe absorption in both genotypes, but the effects were more evident in the knockout mice. Hepcidin administration was also associated with decreased membrane localisation of ferroportin in the duodenum, liver and, most significantly, in the spleen of $H e p c 1^{-1-}$ mice. Hypoferraemia was induced in heterozygous mice by hepcidin treatment, but not in Hepc1 ${ }^{-/-}$mice, $4 \mathrm{~h}$ after injection. Interestingly, Fe absorption and serum Fe levels in Hepc1 $1^{-/}$and heterozygous mice fed a low-Fe diet were not affected by hepcidin injection. The present study demonstrates that hepcidin deficiency causes increased Fe absorption. The effects of hepcidin were abolished by dietary Fe deficiency, indicating that the response to hepcidin may be influenced by dietary Fe level or Fe status.

Key words: Hepcidin: Iron absorption: $\mathrm{Hepc1}^{-/-}$mice

Hepcidin, a liver-secreted antimicrobial peptide, plays a central role in the control of systemic Fe homeostasis by inhibiting $\mathrm{Fe}$ absorption and reducing reticuloendothelial Fe sequestration. Hepatic hepcidin expression is regulated by several stimuli including body Fe status ${ }^{(1)}$. The Fe-sensing pathway that regulates hepcidin involves several molecules including HFE high-Fe or haemochromatosis protein, haemojuvelin (HFE2) and transferrin receptor $2^{(2,3)}$. Defects in this Fe-sensing pathway or hepcidin itself result in hereditary haemochromatosis $^{(4-7)}$. The role of hepcidin in Fe homeostasis was revealed in mice lacking the transcription factor upstream stimulatory factor $2(U s f 2)^{(8)}$, which was later proposed to be one of the cis-regulatory elements of hepcidin expression ${ }^{(9)}$. In this mouse model, Usf2 disruption was associated with hepcidin deficiency and subsequent severe tissue Fe overload ${ }^{(8)}$. However, genetic disruption of $U s f 2$ has also been reported to affect glucose-dependent gene expression in the liver ${ }^{(10)}$.

Circulatory $\mathrm{Fe}$ is acquired from dietary $\mathrm{Fe}$ and senescent erythrocytes through the Fe exporter ferroportin expressed in enterocytes and splenic macrophages. Hepcidin has been demonstrated to induce internalisation and degradation of ferroportin in several in vitro models including bone marrow-derived macrophages, the mouse monocyte-macrophage cell line $\mathrm{J} 774$, the rat cardiomyocyte cell line $\mathrm{H} 9 \mathrm{C} 2$ and in cell lines ectopically overexpressing green fluorescent protein (GFP)-tagged ferroportin ${ }^{(11-13)}$. Some in vivo studies have indirectly suggested that this mechanism is important in tissue Fe metabolism. For example, increased ferroportin protein expression in the duodenum, liver and spleen has been shown in several hepcidin-deficient mouse models such as $\mathrm{Hfe} 2^{-/-}$and Usf $2^{-/-}$mice ${ }^{(14,15)}$. An inverse relationship between the hepcidin and duodenal expression of ferroportin and divalent metal transporter 1 (DMT1) protein has also been found in pregnant and Fe-deficient rats ${ }^{(16,17)}$ In contrast, however, hepcidin expression was suppressed in phenylhydrazine-treated rats and was associated with increased DMT1 protein in the duodenum without a change in ferroportin ${ }^{(18)}$. In more direct studies, treatment with synthetic hepcidin and hepcidin-containing conditioned medium reduced DMT1 expression at both RNA and protein levels as well as apical Fe uptake in intestinal cell lines (Caco-2, HuTu80 and HT29) and rat duodenal segments

Abbreviations: \%MT, percentage of mucosal transfer; Hepc1 ${ }^{-/-}$, hepcidin1 knockout; MR, mucosal retention; MT, mucosal transfer; TMU, total mucosal uptake; Usf2, upstream stimulatory factor 2 .

*Corresponding author: Professor A. T. McKie, fax +44 207848 4055, email andrew.t.mckie@kcl.ac.uk 
without affecting basolateral Fe transport or ferroportin expression ${ }^{(19-21)}$. In parallel studies, it has been shown that hepcidin caused a dramatic reduction in ferroportin expression in the THP-1 macrophage cell model (human acute monocytic leukaemia cell line). In agreement with these latter in vitro studies, hepcidin treatment in mice suppressed intestinal Fe uptake but had no effect on relative Fe transfer to blood. A significant reduction in total mucosal uptake (TMU) upon multiple hepcidin injections has been reported in CD1 mice (feeding both control and an $\mathrm{Fe}$ deficient diet) as well as in Hfe wild-type/knockout mice ${ }^{(22)}$. Interestingly, recent studies have shown that hepcidin inhibited Fe transport and enhanced cellular Fe accumulation in Caco-2 cells, suggesting a blockage of Fe efflux albeit with unaltered ferroportin expression ${ }^{(23)}$. Furthermore, hepcidin administration in $\mathrm{C} 57 \mathrm{BL} / 6$ mice resulted in decreased splenic ferroportin expression within $4 \mathrm{~h}$. In contrast, reduced in vivo TMU and duodenal ferroportin expression occurred at $24 \mathrm{~h}$ after injection. A cell type-specific response or differential tissue sensitivity to hepcidin was therefore postulated.

In previous studies, $\mathrm{Fe}$ absorption was measured at 24 or $72 \mathrm{~h}$ after hepcidin injection. However, the effects of hepcidin could be more rapid, and the findings at the $24 \mathrm{~h}$ time point could be secondary effects ${ }^{(22,23)}$. In addition, another key variable in such in vivo experiments is the endogenous production of hepcidin by mice, which could interfere with the effects of exogenous hepcidin. So far, direct in vivo effects of hepcidin have been studied only in wild-type (CD1 and $\mathrm{C} 57 \mathrm{BL} / 6)$ and $\mathrm{Hfe}^{-1-}$ mice that express endogenous hepcidin. The present study was therefore conducted in a mouse model lacking endogenous hepcidin, namely bepcidin 1 knockout $\left(H e p c 1^{-/-}\right)$mice ${ }^{(24)}$, in order to explore the effects of total hepcidin deficiency. Additionally, the effects of hepcidin administration on Fe parameters, Fe absorption and ferroportin expression were also studied at an earlier time point ( $4 \mathrm{~h}$ post-injection) than previously reported.

\section{Experimental methods}

\section{Animal care and hepcidin treatment}

The generation and breeding of $H e p c 1^{-/-}$mice (a mixed $\mathrm{C} 57 \mathrm{BL} / 6 \times 129$ background strain backcrossed for at least five generations on $\mathrm{C} 57 \mathrm{BL} / 6$ ) has previously been reported $^{(24)}$. The previous study has shown no differences in Fe metabolism parameters between Hepc1 wild-type and heterozygous mice ${ }^{(24)}$; hence, heterozygous mice were used as controls for the present study. Male Hepc $1^{-/-}$mice and heterozygous littermates aged 9-12 weeks old were intraperitoneally injected with $10 \mu \mathrm{g}$ of synthetic human hepcidin (Peptide International, Louisville, KY, USA) or an equal volume of sterile saline solution. An in vivo Fe absorption study and sample collection were conducted at $4 \mathrm{~h}$ after the injection. Dietary Fe deficiency was induced by feeding mice a low Fe-purified diet (TD.80396, 4 parts per million Fe; Harlan Teklad, Madison, WI, USA) for 2 weeks. In other experiments, mice were fed on the rat and mouse no. 1 maintenance (RM1) diet (Special Diets Services, Essex, UK).
The dietary composition of the RM1 diet is supplied by the manufacturer as follows: metabolisable energy $10.74 \mathrm{~kJ} / \mathrm{g}$, oil $7 \cdot 42 \%$ energy, protein $17 \cdot 49 \%$ energy, carbohydrate $75.09 \%$ energy, moisture $10 \%$, minerals $33 \cdot 29 \mathrm{~g} / \mathrm{kg}$ (Fe 159.30 parts per million) and vitamins $3.64 \mathrm{~g} / \mathrm{kg}$. Mice were fed ad libitum on diets up until the time of culling. The mice were culled under isoflurane-induced anaesthesia by exsanguination. National guidelines for the care and use of animals were followed. All experimental procedures involving animals were approved by the UK Home Office.

\section{In vivo iron absorption}

In vivo Fe absorption was measured in tied-off duodenal segments as described previously ${ }^{(22)}$. In brief, the experiments were conducted in anaesthetised mice. A duodenal segment was tied at both ends followed by the injection of $250 \mu \mathrm{M}^{5}{ }^{59} \mathrm{FeNTA}_{2}$ (ferric nitrilotriacetate) in physiological buffer $\left(125 \mathrm{~mm}-\mathrm{NaCl}, 3.5 \mathrm{~mm}-\mathrm{KCl}, 10 \mathrm{~mm}-\mathrm{MgCl}_{2}, 1 \mathrm{~mm}-\mathrm{CaCl}_{2}\right.$ and $16 \mathrm{~mm}$-HEPES, $\mathrm{pH} 7 \cdot 4$ ) into the tied-off segment (radiolabelled $\mathrm{Fe}$ was obtained as ${ }^{59} \mathrm{FeCl}_{3}$; Perkin Elmer, Boston, MA, USA). The segment was placed back into the abdominal cavity. After $10 \mathrm{~min}$ incubation, the duodenal segment was flushed with ice-cold saline solution and weighed. Blood, liver and spleen were collected. Radioactivity in tissue samples and blood was measured using a gamma counter (1282 Compugamma; LKB Wallac, Turku, Finland), while carcasses were counted for radioactivity by a high-resolution bulk sample counter (J\&P Engineering, Reading, UK). Radioactivity in the duodenum is referred to as mucosal retention (MR), while radioactivity in carcass and other tissues is regarded as mucosal transfer (MT). TMU is the amount of total radioactive Fe absorbed from the gut lumen, and the percentage of MT $(\% \mathrm{MT})$ is the relative amount of Fe transfer into the body in comparison with total Fe uptake.

\section{Hepcidin quantitative RT-PCR}

RNA was extracted from the liver using TRIzol reagent (Invitrogen, Paisley, UK), and complementary DNA was synthesised using a Transcriptor High Fidelity cDNA Kit (Roche Diagnostics, Mannheim, Germany). Quantitative RT-PCR was performed using the ABI Prism 7000 (Applied Biosystems, Carlsbad, CA, USA) and Universal ProbeLibrary System (Roche Diagnostics). Hepcidin (Hepc1) expression was normalised to $\beta$-actin (Actb) mRNA. The sequence of the utilised primers is listed as follows:

$\begin{array}{ll}A c t b & \text { Forward: CTAAGGCCAACCGTGAAAAG } \\ & \text { Reverse: ACCAGAGGCATACAGGGACA }\end{array}$

Hepc1 Forward: GATGGCACTCAGCACTCG Reverse: GCTGCAGCTCTGTAGTCTGTCT

\section{Measurement of $\mathrm{Hb}$, serum iron and tissue non-haem iron contents}

$\mathrm{Hb}$ was determined spectrophotometrically using the methods described by Beutler ${ }^{(25)}$. Serum Fe was measured with a liquid ferrozine-based Fe reagent (Thermo Electron, Melbourne, 
VIC, Australia). Tissue non-haem Fe levels were determined by a modification of the method of Foy et al. ${ }^{(26)}$, as described by Simpson \& Peters ${ }^{(27)}$.

\section{Western blot analysis of ferroportin}

Membrane protein was extracted by homogenising tissues in $1 \mathrm{ml}$ of lysis buffer $\left(20 \mathrm{~mm}-\mathrm{KH}_{2} \mathrm{PO}_{4}, \quad 0 \cdot 1 \mathrm{~mm}-\mathrm{EDTA}\right.$ and $135 \mathrm{~mm}-\mathrm{KCl})$ and protease inhibitor cocktail (1:200 dilution; Sigma-Aldrich, Poole, UK). The homogenate was centrifuged at $1000 \mathrm{~g}$ for $5 \mathrm{~min}$ at $4^{\circ} \mathrm{C}$. The resulting supernatant was decanted to new tubes and centrifuged at $28500 \mathrm{~g}$ for $1 \mathrm{~h}$ at $4^{\circ} \mathrm{C}$. The supernatant was discarded, and the pellet was resuspended in a buffer containing $20 \mathrm{~mm}-\mathrm{KH}_{2} \mathrm{PO}_{4}, 10 \mathrm{~mm}$-EDTA, $1 \mathrm{~mm}-\mathrm{KCl}$ and protease inhibitor cocktail. Western blot analysis was performed using a primary rabbit anti-mouse metal transporter protein 1 (MTP1) antibody (Alpha Diagnostic, San Antonio, TX, USA) and rabbit anti-actin antibody (SigmaAldrich) in order to detect ferroportin and actin, respectively.

\section{Ferroportin immunofluorescence}

Tissue samples were immersed in tissue-freezing medium (TBS, Durham, NC, USA). The tissue blocks were cut into $5 \mu \mathrm{m}$ sections and mounted on poly-lysine-coated slides (Sigma-Aldrich). The slides were air-dried and fixed in acetone. Ferroportin immunofluorescence was conducted using rabbit anti-mouse ferroportin antiserum (1:100 dilution) ${ }^{(28)}$ and fluorescein isothiocyanate-conjugated antirabbit antibody (Dako Cytomation, Glostrup, Denmark). The images were captured with a DM IRE2 confocal microscope (Leica, Wetzlar, Germany).

\section{Statistical analysis}

Data are presented as means with their standard errors. The comparison of multiple groups for significant effects of two variables (hepcidin injection and genotype) was determined by two-way ANOVA with a Bonferroni post hoc test. Relative hepcidin mRNA expression was analysed by Student's unpaired $t$ test. A $P$ value less than 0.05 was considered as significant. All statistical analyses were performed using GraphPad Prism 4 software (GraphPad Software, Inc., La Jolla, CA, USA).

\section{Results}

Hepcidin inhibited iron absorption in Hepc1 ${ }^{-1-}$ mice

In order to assess the influence of hepcidin on intestinal Fe absorption, radiolabelled Fe uptake was performed in vivo using tied-off duodenal segments from anaesthetised mice fed a standard laboratory diet.

In comparison with heterozygous littermates, Hepc $1^{-/-}$ mice had about a two- to threefold increase in TMU, MR and MT $(P<0.001$ for the effects of genotype on TMU and MT; $P=0.001$ for the effect of genotype on MR), whereas no significant difference was found in \%MT (Table 1). Hepcidin administration reduced TMU and MT in both genotypes but with significant reductions in $H e p c 1^{-/-}$mice $4 \mathrm{~h}$ after the treatment $(P=0.003$ and 0.001 for the effects of hepcidin on TMU and MT, respectively). Interestingly, a borderline significant effect of hepcidin treatment on \%MT is indicated by two-way ANOVA (Table 1).

Tissue distribution of the absorbed ${ }^{59} \mathrm{Fe}$ was also compared between hepcidin-injected $H e p c 1^{-/-}$and heterozygous mice. $H e p c 1^{-/-}$mice demonstrated significantly higher radioactivity in the liver, while less ${ }^{59} \mathrm{Fe}$ was found in the spleen and erythrocytes compared with heterozygous littermates $(P<0.001$ for the effects of genotype on radioactivity in the liver; $P=0.002$ and 0.030 for the effects of genotype on radioactivity in the spleen and erythrocytes, respectively; Table 2).

\section{Hepcidin administration did not reduce serum iron in Hepc $^{-1-}$ mice}

Serum and tissue Fe levels were also measured to determine the effect of hepcidin on $\mathrm{Fe}$ compartmentalisation. As expected, Hepc $1^{-/-}$mice contained significantly higher serum Fe and liver non-haem Fe levels compared with heterozygous littermates $(P<0.001$ for the effects of genotype on serum Fe and liver non-haem Fe levels; Table 1). Notably, hepcidin treatment resulted in a $37 \%$ reduction of serum $\mathrm{Fe}$

Table 1. Effects of hepcidin on iron parameters and iron absorption in mice fed a standard laboratory diet

(Mean values with their standard errors)

\begin{tabular}{|c|c|c|c|c|c|c|c|c|c|c|c|}
\hline & \multicolumn{2}{|c|}{$\begin{array}{c}\text { Het }+ \text { saline } \\
(n 6)\end{array}$} & \multicolumn{2}{|c|}{$\begin{array}{c}\text { Het }+ \text { hepcidin } \\
\text { (n6) }\end{array}$} & \multicolumn{2}{|c|}{$\begin{array}{c}\mathrm{KO}+\text { saline } \\
\text { (n 6) }\end{array}$} & \multicolumn{2}{|c|}{$\begin{array}{c}\mathrm{KO}+\text { hepcidin } \\
(n 6)\end{array}$} & \multicolumn{3}{|c|}{$P$ (two-way ANOVA) } \\
\hline & Mean & SEM & Mean & SEM & Mean & SEM & Mean & SEM & Genotype & Hepcidin & Genotype $\times$ hepcidin \\
\hline Serum Fe $(\mu \mathrm{M})$ & 33.30 & $1 \cdot 79$ & $20 \cdot 98^{*}$ & $3 \cdot 67$ & $44 \cdot 73$ & $2 \cdot 11$ & 41.35 & $3 \cdot 80$ & $<0.001$ & 0.012 & $0 \cdot 184$ \\
\hline $\begin{array}{l}\text { Liver non-haem Fe } \\
\quad \text { (nmol/mg wet weight) }\end{array}$ & $1 \cdot 85$ & $0 \cdot 16$ & $2 \cdot 06$ & $0 \cdot 19$ & 24.83 & 5.43 & $26 \cdot 69$ & $4 \cdot 68$ & $<0.001$ & 0.776 & 0.820 \\
\hline TMU (pmol/mg per $10 \mathrm{~min}$ ) & $60 \cdot 50$ & $4 \cdot 88$ & $46 \cdot 05$ & $6 \cdot 31$ & $146 \cdot 70$ & 13.35 & 94.06†† & $12 \cdot 89$ & $<0.001$ & 0.003 & 0.073 \\
\hline $\mathrm{MR}(\mathrm{pmol} / \mathrm{mg}$ per $10 \mathrm{~min})$ & $25 \cdot 15$ & $2 \cdot 24$ & 23.50 & $5 \cdot 63$ & $52 \cdot 81$ & 8.65 & 47.94 & $7 \cdot 67$ & 0.001 & 0.622 & 0.808 \\
\hline MT (pmol/mg per $10 \mathrm{~min})$ & 35.35 & 3.59 & 22.55 & $2 \cdot 80$ & 93.89 & $12 \cdot 10$ & 46.12††† & $7 \cdot 26$ & $<0.001$ & 0.001 & 0.029 \\
\hline$\% \mathrm{MT}$ & $58 \cdot 16$ & $2 \cdot 90$ & $52 \cdot 62$ & $6 \cdot 89$ & 63.47 & 4.65 & $49 \cdot 25$ & $4 \cdot 73$ & 0.847 & 0.062 & 0.397 \\
\hline
\end{tabular}

Het, heterozygote; $\mathrm{KO}, \mathrm{Hepc1}^{-1-}$ mice; TMU, total mucosal uptake; MR, mucosal retention; MT, mucosal transfer; \%MT, percentage of mucosal transfer.

* Mean value was significantly different from that of the heterozygote control $(P<0.05)$.

Mean values were significantly different from those of the $H e p c 1^{-1-}$ control: $\dagger \dagger P<0.01, \dagger_{\dagger} P<0.001$. 
Table 2. Distribution of gastrointestinally absorbed ${ }^{59} \mathrm{Fe}$ in mice fed a standard laboratory diet ${ }^{\star}$

(Mean values with their standard errors)

\begin{tabular}{|c|c|c|c|c|c|c|c|c|c|c|c|}
\hline \multirow[b]{2}{*}{ Relative radioactivity (\%) } & \multicolumn{2}{|c|}{$\begin{array}{l}\text { Het + saline } \\
\quad(n 10)\end{array}$} & \multicolumn{2}{|c|}{$\begin{array}{l}\text { Het }+ \text { hepcidin } \\
\quad(n 13)\end{array}$} & \multicolumn{2}{|c|}{$\begin{array}{c}\mathrm{KO}+\text { saline } \\
(n 6)\end{array}$} & \multicolumn{2}{|c|}{$\begin{array}{c}\mathrm{KO}+\text { hepcidin } \\
(n 8)\end{array}$} & \multicolumn{3}{|c|}{$P$ (two-way ANOVA) } \\
\hline & Mean & SEM & Mean & SEM & Mean & SEM & Mean & SEM & Genotype & Hepcidin & Genotype $\times$ hepcidin \\
\hline Liver & 3.44 & $1 \cdot 16$ & $4 \cdot 30$ & 0.67 & 39.75 & 11.93 & $46 \cdot 61$ & $9 \cdot 86$ & $<0.001$ & 0.624 & 0.703 \\
\hline Spleen & 1.82 & 0.68 & 1.90 & 0.33 & 0.30 & 0.08 & 0.64 & 0.24 & 0.002 & 0.610 & 0.746 \\
\hline Erythrocytes & 0.63 & 0.06 & 0.75 & 0.04 & 0.38 & 0.05 & 0.38 & 0.04 & 0.030 & 0.651 & 0.659 \\
\hline
\end{tabular}

Het, heterozygote; $\mathrm{KO}, \mathrm{Hepc1}{ }^{-1-}$ mice.

* Radioactivity in the samples obtained from in vivo Fe absorption is presented relative to the total counts in the body apart from the duodenum. The relative radioactivity in erythrocytes was normalised to the relative radioactivity of the whole blood samples. Statistical analysis was performed by two-way ANOVA with a Bonferroni post hoc test.

in heterozygotes $(33.3$ (SEM 1.8) v. 21.0 (SEM 3.7) $\mu \mathrm{M}, P<0.05$ by the Bonferroni post hoc test; Table 1), while no change in serum Fe levels was found in Hepc1 ${ }^{-1-}$ mice.

\section{Hepcidin injection suppressed endogenous hepcidin expression in heterozygous mice and ferroportin} expression in $\mathrm{Hepc}^{-1-}$ mice

Quantitative RT-PCR suggested a significant reduction in liver hepcidin expression in heterozygous mice upon exogenous hepcidin treatment (Fig. 1).

Western blot analysis showed higher ferroportin protein expression in the spleen and liver along with a trend towards increased ferroportin expression in the duodenum of Hepc $1^{-1-}$ mice compared with heterozygous mice $(P=$ $0 \cdot 109, P<0.001$ and $P=0.002$ for the effects of genotype on ferroportin expression in the duodenum, liver and spleen, respectively; Figs. 2-4). Intraperitoneal hepcidin injection in the knockout mice significantly reduced ferroportin protein expression in the spleen $(P<0.05$ by the Bonferroni post hoc test; Fig. 4). No change in ferroportin expression upon hepcidin administration was found in the heterozygotes.

The effect of hepcidin on ferroportin was further investigated by immunofluorescence. Ferroportin staining in the duodenum, liver and spleen was stronger in $H e p c 1^{-/-}$mice than in heterozygotes (Fig. 5). Upon hepcidin administration, ferroportin expression in all three tissues of the treated knockout mice was reduced in comparison with control Hepc $1^{-/-}$ mice. However, the difference between the control and treatment groups was not distinct in heterozygous mice. Similar to Usf $2^{-1-}$ mice ${ }^{(15)}$, ferroportin immunofluorescence in the Hepc $1^{-/-}$liver was detected predominantly in Kupffer cells.

\section{Iron deficiency altered the effects of hepcidin treatment}

To explore whether the effects of hepcidin depended on Fe status/dietary Fe levels, mice were fed a low-Fe diet for 2 weeks before the in vivo Fe absorption study. Under the Fedeficient diet treatment, Hepc $1^{-/-}$mice had significantly increased serum Fe as well as liver non-haem Fe levels compared with heterozygous mice $(P<0.001$ for the effects of genotype on serum Fe and liver non-haem Fe levels; Table 3). A significant effect of hepcidin on serum Fe $(P=0.016)$ was indicated by two-way ANOVA. However, no significant difference in serum $\mathrm{Fe}$ and liver non-haem Fe levels was found between the saline- and hepcidin-treated groups.

Under low-Fe diet feeding, heterozygous mice generally had higher TMU than those on the RM1 diet. TMU was significantly higher, and MT was marginally increased in Hepc1 ${ }^{-/-}$ compared with heterozygous mice $(P=0.044$ and 0.069 for the effects of genotype on TMU and MT, respectively; Table 3). No significant difference in MR and \% MT was found between heterozygous and knockout mice. Furthermore, hepcidin injection had no significant effect on any of the Fe absorption parameters in either genotype.

\section{Discussion}

Fe loading in most of hereditary haemochromatosis patients is caused by continuously enhanced Fe absorption due to reduced hepcidin levels. Fe absorption has been shown to be higher in $H f^{-1-}$ mice but only to a small extent ${ }^{(22)}$. In the present study, Fe absorption was measured in vivo in tied-off duodenal segments of Hepc $1^{-/-}$mice and heterozygous littermates. This mouse model has previously been shown to have severe systemic Fe overload with splenic macrophage sparing, whereas no difference in haematological

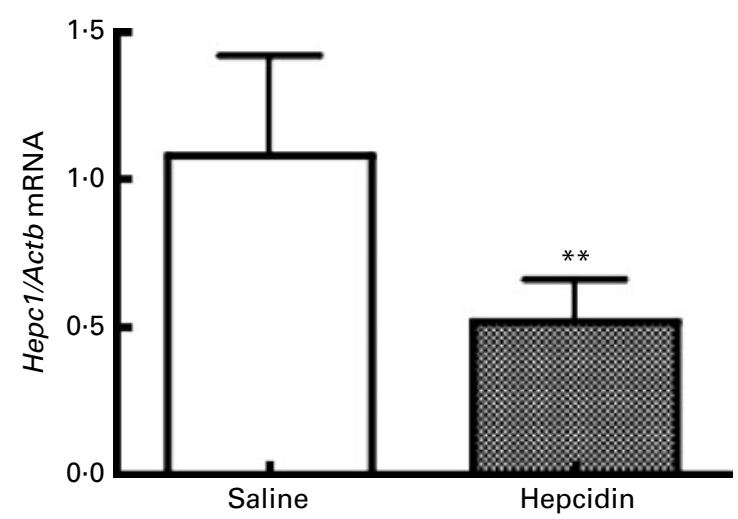

Fig. 1. Effect of exogenous hepcidin treatment on endogenous hepcidin expression in Hepc1 heterozygous mice. Quantitative RT-PCR of hepcidin mRNA (Hepc1) from the liver of saline ( $\square$ )- and hepcidin ( $\square$ )-treated Hepc1 heterozygous mice. Relative expression was acquired by normalising Hepc1 mRNA to $\beta$-actin (Actb) mRNA. Values are means, with standard errors represented by vertical bars, for the fold change as compared with the saline-treated group $(n 4)$. The samples were measured in triplicate. Statistical analysis was performed by Student's unpaired $t$ test. ${ }^{* *}$ Mean value was significantly different from that of the heterozygote control $(P<0.01)$. 
(a)

Heterozygote

Knockout

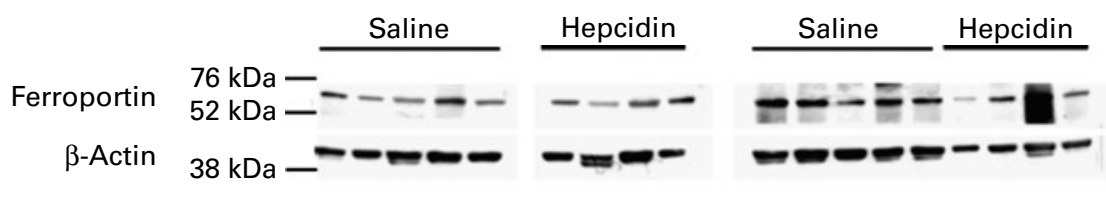

(b)

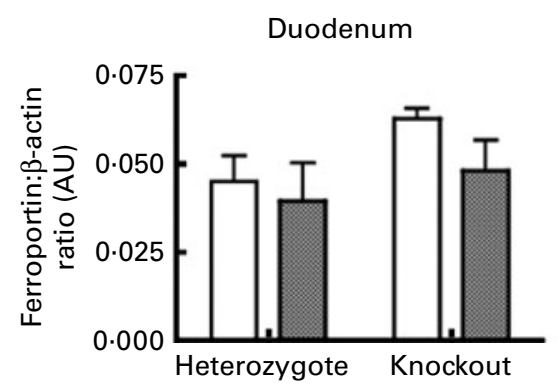

Fig. 2. Effect of hepcidin administration on duodenal ferroportin expression in heterozygous and Hepc1 ${ }^{-1-}$ mice. (a) Western blot analysis of ferroportin $(50 \mu \mathrm{g}$ crude membrane preparation) from the duodenum of saline ( $\square$ )-/hepcidin ( $\square$ )-injected heterozygous and Hepc1 ${ }^{-1-}$ mice. Molecular weight markers are indicated on the left. (b) Blot densitometry as obtained by ImageJ software (National Institutes of Health, Bethesda, MD, USA). Ferroportin expression was normalised to the expression of $\beta$-actin and presented in arbitrary unit (AU). Values are means, with standard errors represented by vertical bars ( $n 5,4,5$ and 4 , respectively). Statistical analysis was performed by two-way ANOVA with a Bonferroni post hoc test. No significant effects of genotype, hepcidin and genotype $\times$ hepcidin: $P=0 \cdot 109,0 \cdot 207,0.560$, respectively.

and Fe parameters was detected between wild-type and heterozygous mice ${ }^{(24)}$. Furthermore, genetic disruption of Hepc1 had no effect on body weight until the age of 8 months when significant weight loss was noted in the knockout mice. In addition, unpublished results in our laboratory found no difference in body weight and food intake between Hepc $1^{-/-}$mice and heterozygous littermates (P. Masaratana, unpublished results).

Under standard laboratory diet feeding, genetic disruption of the Hepc1 gene resulted in increased apical Fe uptake and intestinal $\mathrm{Fe}$ retention. However, no change in proportional basolateral $\mathrm{Fe}$ transfer was found. These findings are therefore in agreement with previous observations that hepcidin deficiency is associated with enhanced intestinal absorption and subsequent Fe overload. Most of the gastrointestinally absorbed Fe was taken up by the liver, explaining the extensive liver Fe loading found in this mouse model. A similar finding was also observed in hypotransferrinaemic mice ${ }^{(29-31)}$.

The present study demonstrates that hepcidin had rapid inhibitory effects on Fe absorption particularly in Hepc $1^{-/-}$ mice. The administration of synthetic hepcidin in Hepc1 ${ }^{-1-}$ mice caused reductions in mucosal Fe uptake and MT at $4 \mathrm{~h}$ after treatment without altering the tissue distribution of absorbed Fe. Hepc $1^{-1-}$ mice may be more sensitive to hepcidin treatment than heterozygous mice, as the effects of

(a)

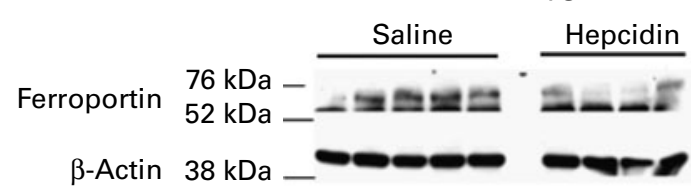

(b)

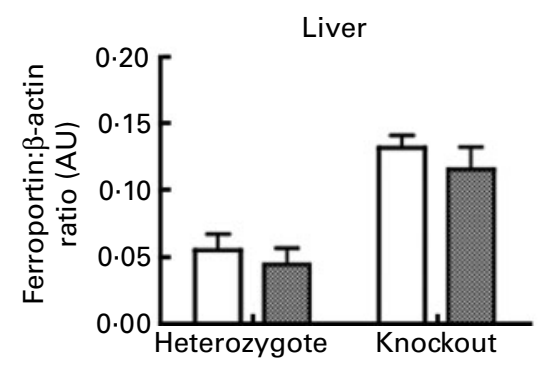

Fig. 3. Effect of hepcidin administration on ferroportin expression in the liver of heterozygous and Hepc1 ${ }^{-1-}$ mice. (a) Western blot analysis of ferroportin (100 $\mu \mathrm{g}$ crude membrane preparation) from the liver of saline $(\square)$-/hepcidin ( $\square$ )-injected heterozygous and Hepc1 ${ }^{-1-}$ mice. Molecular weight markers are indicated on the left. (b) Blot densitometry as obtained by ImageJ software (National Institutes of Health, Bethesda, MD, USA). Ferroportin expression was normalised to the expression of $\beta$-actin and presented in arbitrary unit (AU). Values are means, with standard errors represented by vertical bars ( $n 5,4,5$ and 4 , respectively). Statistical analysis was performed by two-way ANOVA with Bonferroni post hoc test. Mean values were significant for the effect of genotype: $P<0.001$. No significant effects of hepcidin and genotype $\times$ hepcidin: $P=0.301$ and 0.824 , respectively. 
(a)

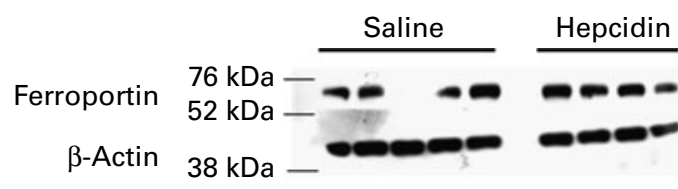

Knockout

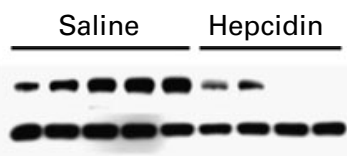

(b)

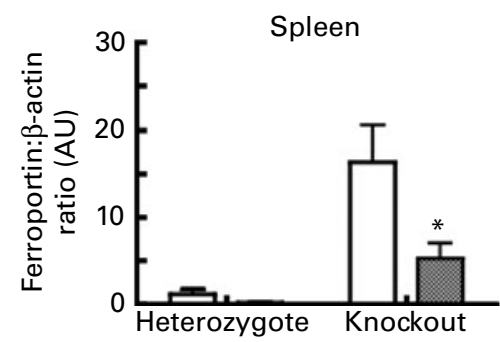

Fig. 4. Effect of hepcidin administration on ferroportin expression in the spleen of heterozygous and $H e p c 1^{-1-}$ mice. (a) Western blot analysis of ferroportin

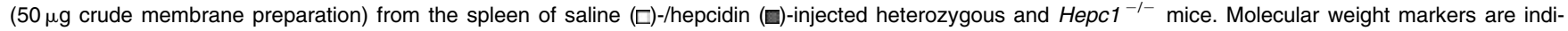
cated on the left. (b) Blot densitometry as obtained by ImageJ software (National Institutes of Health, Bethesda, MD, USA). Ferroportin expression was normalised to the expression of $\beta$-actin and presented in arbitrary unit (AU). Values are means, with standard errors represented by vertical bars $(n 5,4,5$ and 4 , respectively). Statistical analysis was performed by two-way ANOVA with a Bonferroni post hoc test. Mean values were significant for the effect of genotype and hepcidin: $P=0.002,0.037$, respectively. No significant effect of genotype $\times$ hepcidin: $P=0.074$. ${ }^{*}$ Mean value was significantly different as from that of the knockout control $(P<0.05)$.

hepcidin on Fe absorption are more pronounced in the former group. This is also supported by a significant interaction between the effect of genotype and hepcidin on MT as demonstrated by two-way ANOVA. Notably, hepcidin injection in $H e p c 1^{-/-}$mice exerted the strongest effect on MT. A borderline reduction in \%MT upon hepcidin treatment was also found in the knockout mice, suggesting that hepcidin may modulate the basolateral transfer of the absorbed $\mathrm{Fe}$ which involves ferroportin.
Upon Fe-deficient diet treatment, liver non-haem Fe levels were generally lower than the mice maintained under the standard diet across the four groups, suggesting that Fe status was affected by this dietary treatment regimen. Notably, the differences in Fe absorption between Hepc1 ${ }^{-/-}$and heterozygous mice became less apparent under Fe-deficient diet feeding conditions. The effects of genotype of TMU, MR and MT are less significant than those seen in the mice fed a normal commercial diet. It is likely that the effects of Fe

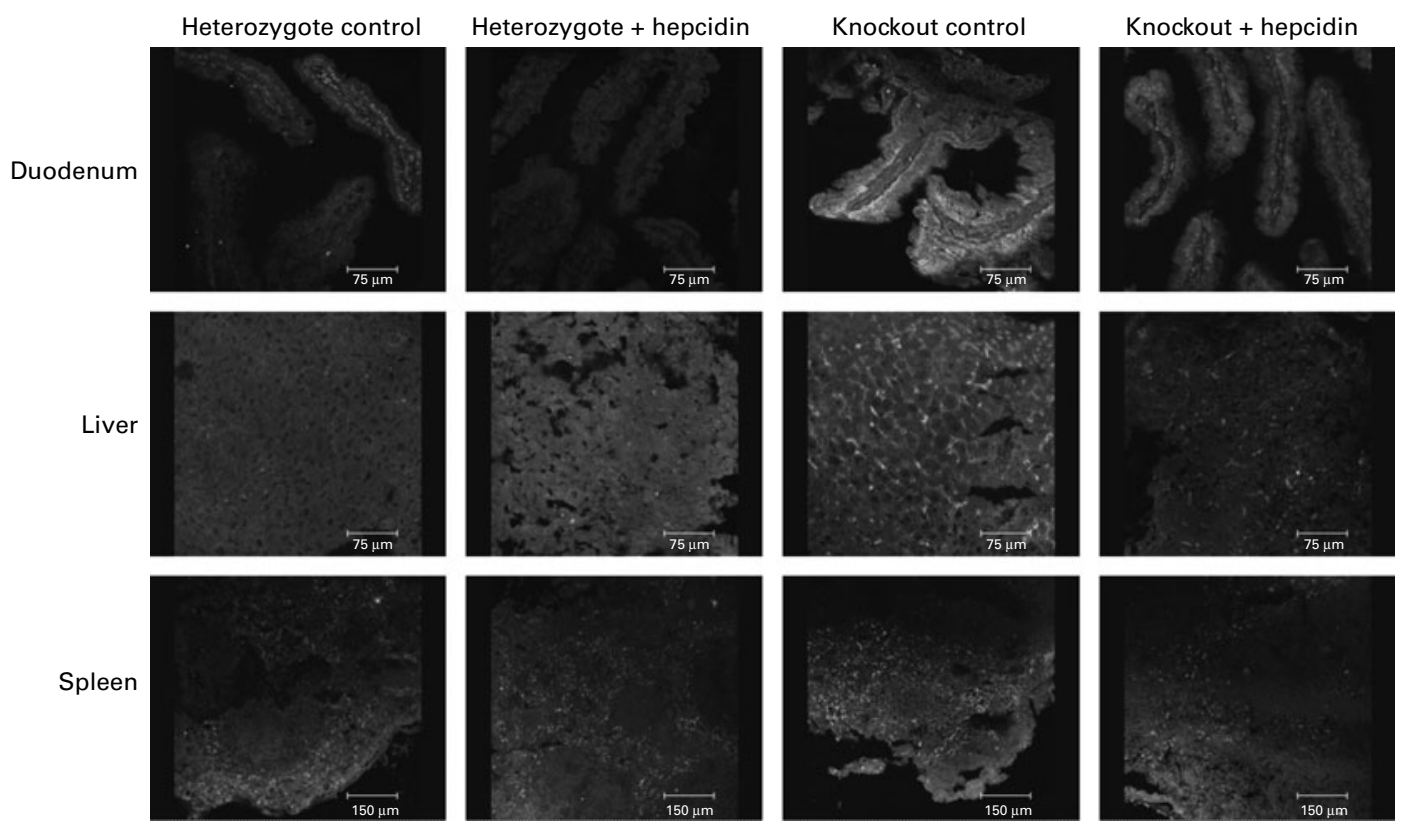

Fig. 5. Immunofluorescence study of the effect of hepcidin administration on ferroportin expression in heterozygous and Hepc1 ${ }^{-/-}$mice. The expression and localisation of ferroportin in the duodenum, liver and spleen of saline- or hepcidin-injected heterozygous/Hepc1 ${ }^{-/-}$mice was demonstrated through the immunofluorescence technique. Ferroportin protein was visualised as green fluorescence, and the nuclei were counterstained in red. Images were captured from a Leica DM IRE2 confocal microscope (Leica, Wetzlar, Germany). Original magnification, $400 \times$ (top two rows), $200 \times$ (bottom row). 
Table 3. Effects of hepcidin on iron absorption in mice fed an iron-deficient diet

(Mean values with their standard errors)

\begin{tabular}{|c|c|c|c|c|c|c|c|c|c|c|c|}
\hline & \multicolumn{2}{|c|}{$\begin{array}{l}\text { Het }+ \text { saline } \\
\quad(n 10)\end{array}$} & \multicolumn{2}{|c|}{$\begin{array}{l}\text { Het }+ \text { hepcidin } \\
\quad(n 13)\end{array}$} & \multicolumn{2}{|c|}{$\begin{array}{c}\mathrm{KO}+\text { saline } \\
(n 6)\end{array}$} & \multicolumn{2}{|c|}{$\begin{array}{c}\mathrm{KO}+\text { hepcidin } \\
(n 8)\end{array}$} & \multicolumn{3}{|c|}{$P$ (two-way ANOVA) } \\
\hline & Mean & SEM & Mean & SEM & Mean & SEM & Mean & SEM & Genotype & Hepcidin & Genotype $\times$ hepcidin \\
\hline Serum Fe $(\mu M)$ & $32 \cdot 70$ & $2 \cdot 33$ & $22 \cdot 52$ & 1.87 & 57.98 & 8.08 & $48 \cdot 26$ & 4.59 & $<0.001$ & 0.016 & 0.954 \\
\hline $\begin{array}{l}\text { Liver non-haem Fe } \\
\text { (nmol/mg wet weight) }\end{array}$ & $1 \cdot 74$ & 0.84 & 1.65 & 0.25 & $12 \cdot 81$ & $2 \cdot 57$ & $15 \cdot 74$ & 1.79 & $<0.001$ & 0.239 & 0.210 \\
\hline TMU (pmol/mg per $10 \mathrm{~min}$ ) & $101 \cdot 86$ & $17 \cdot 14$ & $116 \cdot 29$ & $16 \cdot 42$ & $166 \cdot 65$ & 35.89 & $146 \cdot 38$ & $25 \cdot 63$ & 0.044 & 0.898 & 0.448 \\
\hline MR (pmol/mg per $10 \mathrm{~min}$ ) & $56 \cdot 50$ & 7.54 & 73.41 & $7 \cdot 52$ & $73 \cdot 86$ & 8.97 & 83.72 & $13 \cdot 62$ & 0.165 & 0.179 & 0.720 \\
\hline MT (pmol/mg per $10 \mathrm{~min}$ ) & $45 \cdot 36$ & $13 \cdot 63$ & $42 \cdot 88$ & $12 \cdot 67$ & 92.79 & 32.08 & $62 \cdot 66$ & $17 \cdot 67$ & 0.069 & 0.369 & 0.445 \\
\hline$\% \mathrm{MT}$ & $38 \cdot 18$ & 6.09 & 30.54 & 5.44 & 47.48 & 8.71 & 38.45 & $5 \cdot 60$ & 0.196 & 0.210 & 0.916 \\
\hline
\end{tabular}

Het, heterozygote; $\mathrm{KO}, \mathrm{Hepc1}^{-1-}$ mice; TMU, total mucosal uptake; MR, mucosal retention; MT, mucosal transfer; \%MT, percentage of mucosal transfer.

deficiency in enhancing Fe absorption were not additive to Hepc1 ablation or, perhaps, Fe absorption had reached its maximum capacity by Hepc1 disruption per se. Hypoxiainducible factor (HIF)- $2 \alpha$ expression is reported to be induced by dietary Fe deficiency; thus, Fe deprivation can exert its effects on $\mathrm{Fe}$ absorption through hepcidin-independent mechanisms ${ }^{(32)}$. Increased protein levels of HIF-2 $\alpha$ were associated with large increases in the duodenal expression of DMT1 and Dcytb, with a trend towards increased duodenal ferroportin and hephaestin levels despite the lack of hepcidin response ${ }^{(32)}$. In agreement with this latter study, intestinalspecific disruption of the HIF pathway counteracted the effects of Fe deficiency on the expression of DMT1 and Dcytb $^{(33)}$. The lack of the effects of hepcidin on Fe absorption in $H e p c 1^{-1-}$ mice under Fe-deficient diet feeding conditions also supports the idea that the effect of hepcidin is related to enterocyte Fe levels and/or Fe status. In contrast to the present study, previous works reported that hepcidin inhibits $\mathrm{Fe}$ absorption independently of dietary Fe level or Fe loading ${ }^{(22)}$. The discrepant effects of hepcidin on Fe absorption in Fedeficient mice between the two studies may result from several factors. Previous studies have been conducted in CD1 mice fed with an Fe-deficient diet for 3 weeks followed by two doses of $50 \mu \mathrm{g}$ hepcidin. Fe absorption was measured at $24 \mathrm{~h}$ after the second hepcidin injection. The present study was performed in mice with a mixed C $57 \mathrm{BL} / 6 \times 129$ background maintained on an Fe-deficient diet for 2 weeks. In addition, only a single dose of $10 \mu \mathrm{g}$ hepcidin was administered $4 \mathrm{~h}$ before the Fe absorption studies. The difference in mouse strain, hepcidin dosage and treatment duration may be responsible for the discordant effects of hepcidin on $\mathrm{Fe}$ absorption.

In order to understand the molecular mechanism behind the hepcidin-mediated inhibition of Fe absorption as well as the hepcidin-ferroportin relationship in hepcidin-deficient subjects, hepcidin and ferroportin expression was studied. Ferroportin immunofluorescence studies showed an inverse relationship between hepcidin and ferroportin expression in the duodenum, liver and spleen of Hepc1 $1^{-/-}$mice. Hepcidin treatment in $H e p c 1^{-/-}$mice was associated with reduced ferroportin staining in all three tissues. In addition, the change in the staining pattern was suggestive for ferroportin internalisation, particularly in the Kupffer cells of hepcidin-injected
Hepc $1^{-/-}$mice (data not shown). Furthermore, Western blot analysis revealed that hepcidin administration significantly reduced ferroportin in the spleen of the knockout mice while reductions in the duodenum and liver were marginal, which was probably due to high individual variation in ferroportin expression. These data suggest that hepcidin influenced ferroportin expression in all three tissues, with a more pronounced effect in the spleen. Hepcidin has previously been shown to inhibit ferroportin expression only in the spleen ${ }^{(21)}$. However, hepcidin-mediated ferroportin degradation has recently been reported in primary mouse hepatocytes $^{(34)}$. It should also be noted that in vivo ferroportin expression could be influenced by several factors in addition to hepcidin. This is evident in mice with intestine-specific iron-responsive protein (IRP) 1 and IRP2 ablation, which contain higher ferroportin protein levels in the duodenum despite increased hepcidin expression ${ }^{(35)}$. This information suggests that the effects of hepcidin on duodenal ferroportin expression can be overridden by IRP or transcriptional controls. The implication of this regulation remains to be elucidated. Interestingly, exogenous hepcidin injection was shown to suppress endogenous hepcidin expression in heterozygous mice. This could be a direct negative feedback control from hepcidin injection or a secondary effect of hypoferraemia induced by hepcidin treatment. Hence, endogenous hepcidin suppression might be responsible for the lack of significant effects of exogenous hepcidin on Fe absorption and splenic ferroportin expression in heterozygotes.

In addition, the injection of $10 \mu \mathrm{g}$ hepcidin failed to reduce serum $\mathrm{Fe}$ in $H e p c 1^{-/-}$mice despite hypoferraemia induced by the same dose of hepcidin in heterozygous littermates. This finding may indicate different ferrokinetics or tissue hepcidin sensitivity between Hepc $1^{-/-}$mice and heterozygous littermates. Notably, Western blot analysis showed that although hepcidin reduced splenic ferroportin in knockout mice, the protein levels are still higher than in heterozygous mice. This may be responsible for the lack of change in serum Fe upon hepcidin treatment in $H e p c 1^{-/-}$mice. A significant effect of hepcidin on serum $\mathrm{Fe}$ has been found to be in agreement with findings reported by Rivera et al. ${ }^{(36)}$, which were obtained from similar strain mice fed a similar diet. Note that their study involved small groups of mice in mixed sex while we used larger groups of male mice only, 
as sex is known to affect Fe metabolism ${ }^{(37)}$. It should also be noted that hepcidin used in the two studies was obtained from different sources. Collectively, our data suggest that the effects of exogenous hepcidin on serum $\mathrm{Fe}$ and $\mathrm{Fe}$ absorption may be affected by Fe status and/or endogenous hepcidin levels. Further studies are required with higher hepcidin dosages in order to explore these issues.

In conclusion, the crucial role of hepcidin in the pathogenesis of hereditary Fe overload was demonstrated in a Hepc $1^{-1-}$ mouse model. Hepcidin deficiency was associated with a two- to threefold increase in Fe absorption and significantly higher uptake of absorbed $\mathrm{Fe}$ by the liver. In addition, exogenous hepcidin administration was shown to rapidly inhibit Fe absorption especially in $H e p c 1^{-/-}$mice. Reduced ferroportin expression in response to hepcidin treatment was found particularly in the spleen. Finally, the response to hepcidin treatment seems to differ between $H e p c 1^{-1-}$ and heterozygous mice and is not observed in mice fed a low-Fe diet, suggesting that dietary Fe levels or Fe status may influence the effects of hepcidin on Fe metabolism.

\section{Acknowledgements}

The present study was supported by a grant from the European Commission (LSHM-CT-2006-037296: EUROIRON1). P. M.'s studentship was supported by the Overseas Research Students Awards Scheme and Anandamahidol Foundation. The authors have no conflicts of interest. P. M., R. J. S. and A. T. M. designed the study; P. M. and A. H. L. conducted the study; P. M., G. O. L.-D., R. J. S. and A. T. M. analysed the data; S. V. provided Hepc1 $1^{-/}$mice for the study; P. M., R. J. S. and A. T. M. wrote the manuscript; G. O. L. and S. V. revised the manuscript; A. T. M. had the primary responsibility for the final content.

\section{References}

1. Pigeon C, Ilyin G, Courselaud B, et al. (2001) A new mouse liver-specific gene, encoding a protein homologous to human antimicrobial peptide hepcidin, is overexpressed during iron overload. J Biol Chem 276, 7811-7819.

2. Goswami T \& Andrews NC (2006) Hereditary hemochromatosis protein, HFE, interaction with transferrin receptor 2 suggests a molecular mechanism for mammalian iron sensing. J Biol Chem 281, 28494-28498.

3. Lin L, Goldberg YP \& Ganz T (2005) Competitive regulation of hepcidin mRNA by soluble and cell-associated hemojuvelin. Blood 106, 2884-2889.

4. Feder JN, Gnirke A, Thomas W, et al. (1996) A novel MHC class I-like gene is mutated in patients with hereditary haemochromatosis. Nat Genet 13, 399-408.

5. Papanikolaou G, Samuels ME, Ludwig EH, et al. (2004) Mutations in HFE2 cause iron overload in chromosome 1qlinked juvenile hemochromatosis. Nat Genet 36, 77-82.

6. Roetto A, Papanikolaou G, Politou M, et al. (2003) Mutant antimicrobial peptide hepcidin is associated with severe juvenile hemochromatosis. Nat Genet 33, 21-22.

7. Camaschella C, Roetto A, Cali A, et al. (2000) The gene TFR2 is mutated in a new type of haemochromatosis mapping to 7q22. Nat Genet 25, 14-15.
8. Nicolas G, Bennoun M, Devaux I, et al. (2001) Lack of hepcidin gene expression and severe tissue iron overload in upstream stimulatory factor 2 (USF2) knockout mice. Proc Natl Acad Sci U S A 98, 8780-8785.

9. Bayele HK, McArdle H \& Srai SK (2006) Cis and trans regulation of hepcidin expression by upstream stimulatory factor. Blood 108, 4237-4245.

10. Vallet VS, Henrion AA, Bucchini D, et al. (1997) Glucosedependent liver gene expression in upstream stimulatory factor $2^{-/-}$mice. J Biol Chem 272, 21944-21949.

11. Delaby C, Pilard N, Goncalves AS, et al. (2005) Presence of the iron exporter ferroportin at the plasma membrane of macrophages is enhanced by iron loading and down-regulated by hepcidin. Blood 106, 3979-3984.

12. Ge XH, Wang Q, Qian ZM, et al. (2009) The iron regulatory hormone hepcidin reduces ferroportin 1 content and iron release in H9C2 cardiomyocytes. J Nutr Biochem 20, $860-865$.

13. Nemeth E, Tuttle MS, Powelson J, et al. (2004) Hepcidin regulates cellular iron efflux by binding to ferroportin and inducing its internalization. Science 306, 2090-2093.

14. Huang FW, Pinkus JL, Pinkus GS, et al. (2005) A mouse model of juvenile hemochromatosis. J Clin Invest $\mathbf{1 1 5}$, 2187-2191.

15. Viatte L, Lesbordes-Brion JC, Lou DQ, et al. (2005) Deregulation of proteins involved in iron metabolism in hepcidindeficient mice. Blood 105, 4861-4864.

16. Millard KN, Frazer DM, Wilkins SJ, et al. (2004) Changes in the expression of intestinal iron transport and hepatic regulatory molecules explain the enhanced iron absorption associated with pregnancy in the rat. Gut 53, 655-660.

17. Frazer DM, Wilkins SJ, Becker E, et al. (2002) Hepcidin expression inversely correlates with the expression of duodenal iron transporters and iron absorption in rats. Gastroenterology 123, 835-844.

18. Frazer DM, Inglis HR, Wilkins SJ, et al. (2004) Delayed hepcidin response explains the lag period in iron absorption following a stimulus to increase erythropoiesis. Gut $\mathbf{5 3}$, 1509-1515.

19. Yamaji S, Sharp P, Ramesh B, et al. (2004) Inhibition of iron transport across human intestinal epithelial cells by hepcidin. Blood 104, 2178-2180.

20. Mena NP, Esparza A, Tapia V, et al. (2008) Hepcidin inhibits apical iron uptake in intestinal cells. Am J Physiol Gastrointest Liver Physiol 294, G192-G198.

21. Chaston T, Chung B, Mascarenhas M, et al. (2008) Evidence for differential effects of hepcidin in macrophages and intestinal epithelial cells. Gut 57, 374-382.

22. Laftah AH, Ramesh B, Simpson RJ, et al. (2004) Effect of hepcidin on intestinal iron absorption in mice. Blood $\mathbf{1 0 3}$, 3940-3944.

23. Chung B, Chaston T, Marks J, et al. (2009) Hepcidin decreases iron transporter expression in vivo in mouse duodenum and spleen and in vitro in THP-1 macrophages and intestinal Caco-2 cells. J Nutr 139, 1457-1462.

24. Lesbordes-Brion JC, Viatte L, Bennoun M, et al. (2006) Targeted disruption of the hepcidin 1 gene results in severe hemochromatosis. Blood 108, 1402-1405.

25. Beutler E (1971) Red Cell Metabolism: A Manual of Biochemical Methods. New York/London: Grune \& Stratton Press.

26. Foy AL, Williams HL, Cortell S, et al. (1967) A modified procedure for the determination of nonheme iron in tissue. Anal Biochem 18, 559-563. 
27. Simpson RJ \& Peters TJ (1990) Forms of soluble iron in mouse stomach and duodenal lumen: significance for mucosal uptake. Br J Nutr 63, 79-89.

28. McKie AT, Marciani P, Rolfs A, et al. (2000) A novel duodenal iron-regulated transporter, IREG1, implicated in the basolateral transfer of iron to the circulation. Mol Cell 5, 299-309.

29. Dickinson TK, Devenyi AG \& Connor JR (1996) Distribution of injected iron 59 and manganese 54 in hypotransferrinemic mice. J Lab Clin Med 128, 270-278.

30. Craven CM, Alexander J, Eldridge M, et al. (1987) Tissue distribution and clearance kinetics of non-transferrin-bound iron in the hypotransferrinemic mouse: a rodent model for hemochromatosis. Proc Natl Acad Sci U S A 84, 3457-3461.

31. Simpson RJ, Lombard M, Raja KB, et al. (1991) Iron absorption by hypotransferrinaemic mice. Br J Haematol 78, $565-570$.

32. Shah YM, Matsubara $\mathrm{T}$, Ito $\mathrm{S}$, et al. (2009) Intestinal hypoxia-inducible transcription factors are essential for iron absorption following iron deficiency. Cell Metab 9 , 152-164.

33. Mastrogiannaki M, Matak P, Keith B, et al. (2009) HIF-2alpha, but not HIF-1alpha, promotes iron absorption in mice. J Clin Invest 119, 1159-1166.

34. Ramey G, Deschemin JC, Durel B, et al. (2010) Hepcidin targets ferroportin for degradation in hepatocytes. Haematologica 95, 501-504.

35. Galy B, Ferring-Appel D, Kaden S, et al. (2008) Iron regulatory proteins are essential for intestinal function and control key iron absorption molecules in the duodenum. Cell Metab 7, 79-85.

36. Rivera S, Nemeth E, Gabayan V, et al. (2005) Synthetic hepcidin causes rapid dose-dependent hypoferremia and is concentrated in ferroportin-containing organs. Blood $\mathbf{1 0 6}$ 2196-2199.

37. Courselaud B, Troadec MB, Fruchon S, et al. (2004) Strain and gender modulate hepatic hepcidin 1 and 2 mRNA expression in mice. Blood Cells Mol Dis 32, 283-289. 